\title{
Short- and Long-term Outcome After Interventional VSD Closure: A Single-Center Experience in Pediatric and Adult Patients
}

\author{
M. Bergmann ${ }^{1}$ - C. P. Germann ${ }^{1}$. J. Nordmeyer ${ }^{1}$ B. B. Peters ${ }^{1}$ - F. Berger ${ }^{1} \cdot$ S. Schubert ${ }^{1,2}$ (1)
}

Received: 13 May 2020 / Accepted: 16 September 2020 / Published online: 3 October 2020

(c) The Author(s) 2020

\begin{abstract}
Interventional closure of congenital ventricular septal defects (VSD) is recording a continuous rise in acceptance. Complete atrioventricular block (cAVB) and residual shunting are major concerns during follow-up, but long-term data for both are still limited. We retrospectively evaluated the outcome of patients with interventional VSD closure and focused on long-term results (>1 year follow-up). Transcatheter VSD closures were performed between 1993 and 2015, in 149 patients requiring 155 procedures (104 perimembranous, 29 muscular, 19 residual post-surgical VSDs, and 3 with multiple defects). The following devices were used: $65 \times$ Amplatzer ${ }^{\mathrm{TM}}$ Membranous VSD Occluder, $33 \times$ Duct Occluder II, $27 \times$ Muscular VSD Occluder, $3 \times$ Duct Occluder I, $24 \times$ PFM-Nit-Occlud $®$, and $3 \times$ Rashkind-Occluder. The median age at time of implantation was 6.2 (0.01-66.1) years, median height $117(49-188) \mathrm{cm}$, and median weight 20.9 (3.2-117) $\mathrm{kg}$. Median follow-up time was $6.2(1.1-21.3)$ years and closure rate was $86.2 \%$ at last follow-up. Complications resulting in device explantation include one case of CAVB with a Membranous VSD occluder 7 days after implantation and four cases due to residual shunt/ malposition. Six (4\%) deaths occurred during follow-up with only one procedural related death from a hybrid VSD closure. Overall, our reported results of interventional VSD closure show favorable outcomes with only one (0.7\%) episode of cAVB. Interventional closure offers a good alternative to surgical closure and shows improved performance by using softer devices. However, prospective long-term data in the current era with different devices are still mandatory to assess the effectiveness and safety of this procedure.
\end{abstract}

Keywords VSD · Congenital heart defect · Intervention · Cardiac catheterization

\section{Introduction}

Ventricular septal defect (VSD) is the most common congenital heart defect with a prevalence of 5.27 diseased children per 1000 live births [1]. Symptoms and therapy are dependent on the size of the defect and age of the patient. Possible complications of an untreated VSD can be pulmonary hyperperfusion and hypertension with Eisenmenger reaction

F. Berger and S. Schubert have contributed equally to this article.

S. Schubert

sschubert@dhzb.de; sschubert@hdz-nrw.de

1 Department of Pediatric Cardiology and Congenital Heart Diseases, German Heart Center Berlin, Augustenburger Platz 1, 13353 Berlin, Germany

2 Clinic for Pediatric Cardiology and Congenital Heart Defects, Herz- Und Diabeteszentrum NRW, Ruhr University of Bochum, Georgstraße 11, 32545 Bad Oeynhausen, Germany after several years $[2,3]$. In small children with large defects, early frequent treatment by surgical closure is preferred, whereas bigger children can be treated alternatively with transcatheter devices. However, both methods carry a potential risk of complete atrioventricular block (cAVB). Studies show cAVB occurs at a rate of $0.1-6.8 \%$ after interventional VSD closure [4-13] and $<2 \%$ after surgical VSD closure $[14,15]$. Surgical closure can be considered for the majority of patients but disadvantages include the use of general anesthesia, sternotomy, and extracorporeal circulatory support, which results in longer recovery and hospital time [16-18]. Interventional closure can be done with sedation by a minimally invasive transcatheter application via a vein or artery and success is dependent mostly on the type of device. Therefore, the implications of the device used for VSD closure on outcome are presented in this study. Moreover, a special focus on the long-term outcomes of transcatheter VSD treatment, which are still limitedly reported in the international literature, shall be examined. 


\section{Patients and Methods}

We retrospectively reviewed 149 patients with congenital VSD who underwent transcatheter VSD closure between 04/1993 and 05/2015. Further inclusion criteria were perimembranous, muscular, multiple, and residual VSD after postoperative closure. We included both percutaneous and hybrid approaches and only unsuccessful implantations or VSD caused by myocardial infarction were excluded. Patient's general data, device sizes, and echocardiography (ECHO) and electrocardiogram (ECG) examinations at the time of implantation were included. Primary endpoints were residual shunt and arrhythmia including cAVB, death, and explantation of device. Our study received ethical approval from the Charité-Universitätsmedizin Berlin (Ref-Nr. EA2/129/15).

\section{Catheterization Procedure and Follow-up}

The catheterization procedure was performed following standardized operations protocols, as previously published [19]. After the intervention, all patients were assessed by ECHO and monitored by ECG as well as by a Holter monitoring device. A standard of care outpatient routine was conducted at time of discharge, roughly 1, 3, 6, and 12 months afterwards, and then yearly. Post-interventional treatment consisted of Aspirin (3-5 mg/kg/day per os) for 6 months. Follow-up data ( $>1$ year) were reviewed for residual shunting, arrhythmia, device dysfunction, re-intervention or explantation, and occurrence of death including cause of death.

\section{Statistical Analysis}

Data were summarized using Microsoft Excel and presented as median (ranges), mean \pm standard deviation, and percentage as appropriate. GraphPad Prism (Version 8) was utilized to evaluate data by unpaired $t$ test, and $p<0.05$ was considered to be statistically significant.

\section{Results}

\section{Patient Data}

A transcatheter closure of congenital VSD was performed in 149 patients with 155 procedures. The median age was $6.2(0.01-66.1)$ years, median height $117(49-188) \mathrm{cm}$, and median weight $20.9(3.2-117) \mathrm{kg}$ at time of intervention (see Table 1). The mean procedural time was 21.5 (4.4-120) min and the mean dose-area-product was 16035
Table 1 General patient data $(n=149)$

\begin{tabular}{lc}
\hline Gender & \\
Male & $80(53.7 \%)$ \\
Female & $69(46.3 \%)$ \\
Approach & \\
Percutaneous & $142(95.3 \%)$ \\
Hybrid & $7(4.7 \%)$ \\
Amount of interventions & \\
Patients with 1 intervention & $143(96.0 \%)$ \\
Patients with 2 interventions & $6(4.0 \%)$ \\
Age at implantation* & $6.3(0.01-66.1)$ years \\
$<1$ years & $19(12.8 \%)$ \\
1-10 years & $70(47.0 \%)$ \\
$>10-20$ years & $28(18.8 \%)$ \\
$>20$ years & $32(21.5 \%)$ \\
Height at implantation** & $118(49-188) \mathrm{cm}$ \\
Bodyweight at implantation** & $21(3.2-117) \mathrm{kg}$ \\
\hline Data as median (range) & \\
$*$ For those patients with multiple interventions we used the date of \\
the first intervention \\
$* * n=146$, due to missing data for 3 patients with Rashkind device
\end{tabular}

(19-413500) milliGray per $\mathrm{cm}^{2}$. In our cohort, 143 patients had only one intervention, while 6 patients required multiple interventions (see Table 1). The location of the VSD was perimembranous $(n=104)$, muscular $(n=29)$, residual post-surgical VSDs $(n=19)$, and multiple defects $(n=3)$. A transfemoral approach was used in 142 patients and 7 hybrid interventions were included. The following devices were used: $65 \times$ Amplatzer ${ }^{\mathrm{TM}}$ Membranous VSD Occluder (VSD Memb), $27 \times$ Amplatzer $^{\text {TM }}$ Muscular VSD Occluder (VSD Musc), $24 \times$ Nit-Occlud ${ }^{\circledR}, 3 \times$ Amplatzer $^{\mathrm{TM}}$ Duct Occluder I (ADO I), and $33 \times$ Amplatzer $^{\mathrm{TM}}$ Duct Occluder II (ADO II). The last two devices were used as "off-label." Additional implantation data are summarized in Table 2.

\section{Device Size}

Patients with a VSD Memb device were significantly older (median age of 11.4 years) at time of implantation, when compared to the other groups (VSD Memb vs. VSD Musc, $p=0.0028$ and vs, ADO II, $p=0.01)$. ADO I and Rashkind-occluder were sidelined due to a small number of patients. The differences in age were congruent, leading to similar significant differences in height and bodyweight (VSD Memb vs. VSD Musc, $p<0.0001$ and vs. ADO II, $p=0.003)$. In line with the differences in age, weight, and height, device size was also significantly different (see Fig. 1a). 
Table 2 Implantation data

\begin{tabular}{|c|c|c|c|c|c|c|}
\hline & $\begin{array}{l}\text { VSD Memb } \\
n=65\end{array}$ & $\begin{array}{l}\text { ADO II } \\
n=33\end{array}$ & $\begin{array}{l}\text { VSD Musc } \\
n=27\end{array}$ & $\begin{array}{l}\text { Nit-Occlud } \\
n=24\end{array}$ & $\begin{array}{l}\text { ADO I } \\
n=3\end{array}$ & $\begin{array}{l}\text { Rashkind } \\
n=3\end{array}$ \\
\hline Age at implantation & $11.4(0.5-65.1)$ & $2.2(0-54.9)$ & $1.9(0.2-34.5)$ & $9.4(0.6-57.7)$ & $9(2 .-46.8)$ & $23.8(12.1-26.9)$ \\
\hline Height in $\mathrm{cm}$ & $155(65-188)$ & $92(49-183)$ & $87(56-176)$ & $137.5(66-185)$ & $132(87-184)$ & l \\
\hline Bodyweight in $\mathrm{kg}$ & $38(6.7-117)$ & $12.5(3.2-104)$ & $11(4.1-64.5)$ & $32.9(5.9-87)$ & $30(12.1-72)$ & I \\
\hline Device size in $\mathrm{mm}$ & $6(4-16)$ & $5(3-6)$ & $8(6-16)$ & $8.5(4-14)$ & $8(6-12)$ & $15(12-17) *$ \\
\hline
\end{tabular}

Data as median (range)

$* n=2$, due to missing data

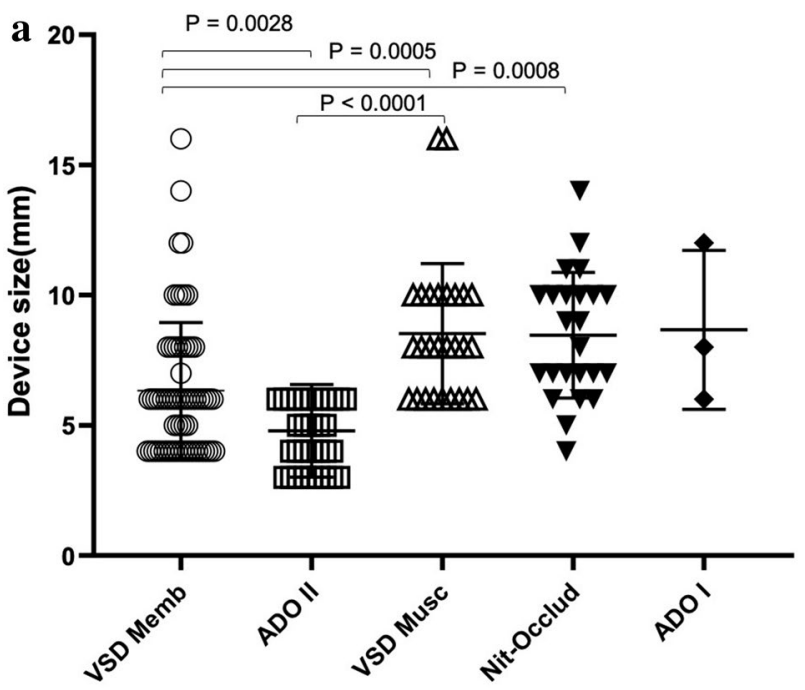

in 109 out of 149 patients and achieved a median follow-up time of 6.2 (1.1-21.3) years with this cohort. The shortest follow-up in the ADO II group was due to the fact that these devices have been used for VSD closure since 2007.

\section{Residual Shunt}

The overall closure rate for all devices was in total 86.2 (61-95) \% at best possible follow-up. The closure rate was influenced by the defect location and highest closure rates ( $>90 \%$ ) were achieved in closure of perimembranous VSD and lowest in residual/post-surgical VSDs (see Fig. 2a). Furthermore, perimembranous VSDs represented the largest group in our study. Sidelining the single multiple VSD, the lowest closure rate was achieved in residual VSDs after surgical treatment. Separating the closure rate according to the devices used and sidelining ADO I and Rashkind devices, the highest closure rates are seen in VSDs closed with VSD Musc (95\%) and with VSD Memb (93\%) (see Fig. 2b). Lowest closure rate of $61 \%$ was reported for Nit-Occlud®. One patient with a Nit-Occlud® developed a new small residual shunt 3 years after perimembranous VSD closure in the $40^{\text {th }}$ week of her pregnancy. This residual shunt showed no significant volume load over time and the device stayed in place.

\section{Arrhythmia During Short-term Follow-up}

Fig. 1 a Overview of the device size measured in $\mathrm{mm}$ for the different devices. Smaller devices had been used for AmplatzerTM VSD Memb and Duct occluder II. b Overview of the patient cohort and the supported follow-up (FU) time

\section{Follow-up}

Overall results for the device groups as duration of followup, death, residual shunts, cAVB, and device explantation have been summarized in Table 3, and illustrated in Fig. 1b. Only four $(2.5 \%)$ devices have been explanted (see also Table 3 ). We were able to collect follow-up data $>1$ year

As reported in Table 3, only 1/149 (rate of $0.7 \%$ ) patient experienced a complete cAVB after percutaneous VSD implantation. In details, an 11-month-old girl with a membranous VSD (see Fig. 3a) was treated using a $6 \mathrm{~mm}$ VSD Memb device (see Fig. 3b). Residual shunting and aortic or tricuspid insufficiency were not seen, which was interpreted as an acceptable post-interventional result. Additionally, during and directly after the intervention, there was only a new right bundle branch block (RBBB) detectable but without events of cAVB (see Fig. 4a, b), and the child was discharged $48 \mathrm{~h}$ after the intervention. An acute cAVB occurred 7 days after VSD closure in a Holter examination during follow-up (see Fig. 4c). As a consequence, the girl 
Table 3 Results for duration of FU, residual shunts, cAVB and device explantation

\begin{tabular}{|c|c|c|c|c|c|c|}
\hline & $\begin{array}{l}\text { VSD Memb } \\
(n=65)\end{array}$ & $\begin{array}{l}\text { ADO II } \\
(n=33)\end{array}$ & $\begin{array}{l}\text { VSD Musc } \\
(n=27)\end{array}$ & $\begin{array}{l}\text { Nit-Occlud } \\
(n=24)\end{array}$ & $\begin{array}{l}\text { Rashkind } \\
(n=3)\end{array}$ & $\begin{array}{l}\text { ADO I } \\
(n=3)\end{array}$ \\
\hline Lost to follow-up & $n=12(18 \%)$ & $n=6(18 \%)$ & $n=7(26 \%)$ & $n=1(4 \%)$ & $n=0$ & $n=1(33 \%)$ \\
\hline Follow-up $>1$ year & $n=48(74 \%)$ & $n=24(73 \%)$ & $n=20(74 \%)$ & $n=21(88 \%)$ & $n=3(100 \%)$ & $n=2(67 \%)$ \\
\hline \multirow[t]{2}{*}{ Follow-up $<1$ year } & $n=5(8 \%)$ & $n=3(9 \%)$ & $n=0$ & $n=2(8 \%)$ & $n=0$ & $n=0$ \\
\hline & $n=53$ & $n=27$ & $n=20$ & $n=23$ & $n=3$ & $n=2$ \\
\hline $\begin{array}{l}\text { Follow-up (years) } \\
\text { (median (range)) }\end{array}$ & $6.5(0.5-13.1)$ & $2.8(0.1-6.3)$ & $8.3(1.8-13.4)$ & $6.2(0.1-12.8)$ & $20.1(15.6-21.3)$ & $8.4(5.8-11.1)$ \\
\hline $\begin{array}{l}\text { 2nd device implantation } \\
\text { 2nd device } \\
\text { Residual shunts }\end{array}$ & $\begin{array}{l}1^{\#} \\
\text { ADO II } \\
5(7.7 \%)\end{array}$ & $\begin{array}{l}2^{\#}, * \\
2 \times \mathrm{ADO} I \mathrm{II} \\
5(15.2 \%)\end{array}$ & $\begin{array}{l}1^{\#} \\
\text { Nit-Occlud } \\
3(11.1 \%)\end{array}$ & $\begin{array}{l}1^{\#} \\
\text { Nit-Occlud } \\
7(29.2 \%)\end{array}$ & 0 & 0 \\
\hline Death & $2(3.1 \%)$ & $1(3 \%)$ & $2(7.4 \%)$ & 0 & $1(33.3 \%)$ & 0 \\
\hline cAVB & 1 & 0 & 0 & 0 & 0 & 0 \\
\hline Device explantation & 2 & 0 & 0 & 2 & 0 & 0 \\
\hline
\end{tabular}

${ }^{1}$ Device implantation is part of total number of implantations

Reason for 2nd device: \#due to additional defect; *due to residual shunting

was sent to surgery for device explantation and surgical VSD closure was performed with a pericardial patch. The postoperative persisting cAVB was treated by temporary DDDPacing and triple administration of Prednisolon, with full recovery within 5 days and in the follow-up. Remarkable are the signs of oversizing (see Fig. 3b), which may be responsible as risk factor for $\mathrm{CAVB}$, especially with the use of the VSD Memb device and prelude for a cAVB might be a new RBBB during or immediately after placement of the device.

\section{Arrhythmia During Long-term Follow-up}

All patients were constantly examined for cardiac arrhythmias during follow-up with the use of ECG and Holter-ECG. Arrhythmia occurred in 4/109 patients (rate of 3.7\%) during long-term follow-up ( $>1$ year) with need for treatment (medication, ablation, or pacemaker implantation). Bradyarrhythmia was detected in only one patient. This patient had an ADO I device and a RBBB, extrasystoles, and bradycardia occurred during long-term FU. This was stable for the last 7 years and RBBB was mainly caused by an underlying diagnosis of Tetralogy of Fallot, peripheral vascular disease, and status post correction. This was not related to the VSD itself because it was already detected prior to the implantation. Two other adult patients with a VSD Musc and a Rashkind device experienced tachyarrhythmia (atrial and ventricular extrasystolia and atrial fibrillation/flutter). In one patient, an underlying severe restrictive cardiomyopathy and supraventricular extrasystoles were detected before VSD closure and this patient needed an ablation and cardiac resynchronization therapy (CRT)-pacemaker 3 months after VSD closure in order to improve anti-tachycardiac treatment. Another patient suffered atrial fibrillation after implantation of the ADO II device. No explantation of a device due to arrhythmia and cAVB occurred during the long-term follow-up period (median 6.2 years).

\section{Mortality}

Mortality occurred in 6/149 (rate of 4\%) patients during follow-up, of which none were related to the device. A procedure-related mortality has been reported in only one patient involving a 4-day-old girl who died after a hybrid approach for residual VSD closure. Perforation of the left ventricular heart wall occurred during the implantation of a $4 \mathrm{~mm}$ VSD Musc device after complex corrective surgery of aortic arch, which was resolved during cardiopulmonary bypass (CPB). However, the patient needed extracorporeal membrane oxygenation (ECMO) due to low cardiac output syndrome afterwards and later weaning from ECMO was not possible. Bleeding complications caused major morbidity and ECMO support was stopped after 24 days.

All other mortalities $(n=5)$ were neither device- nor procedure-related deaths. One female patient died 41 years after surgical VSD closure and 20 years after interventional VSD closure with a Rashkind device due to tachyarrhythmia (VT) without device dysfunction. Another adult patient died at the age of 41 years, 2.1 years after VSD closure with a VSD Memb device due to severe heart failure (HFrEF). Multi-organ failure including chronic kidney failure was the cause of death for another male patient (77 years old) with the implanted VSD Memb device in situ. Another 7-monthold child with a borderline biventricular anatomy achieved a cardiac decompensation 2 weeks after corrective surgery including hybrid VSD closure with a VSD Musc device. Conversion to a functionally univentricular heart as rescue procedure was not sufficient. A patient with transposition 
Fig. 2 a Long-term results for residual shunt according to the defect location during long-term follow-up, number of patients ( $n$ in total $=109$ ); b Long-term results for residual shunt, number of patients ( $n$ in total $=109$ ) according to the implanted VSD device a

80

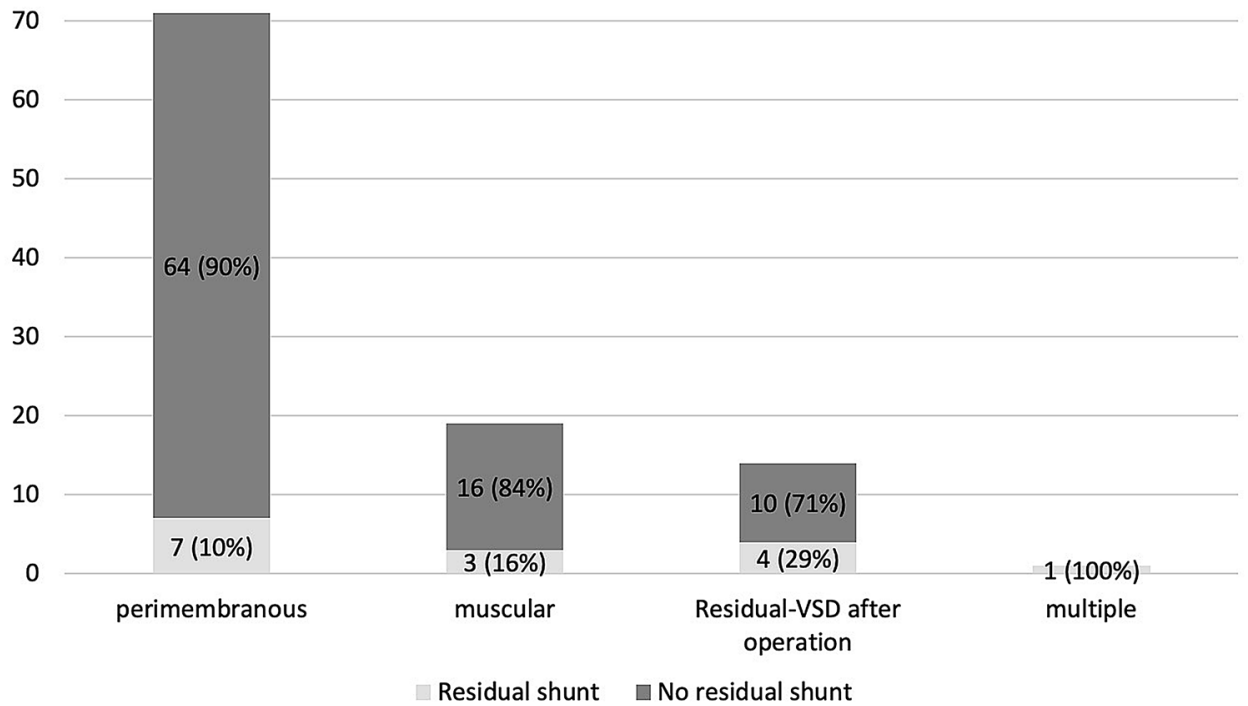

b

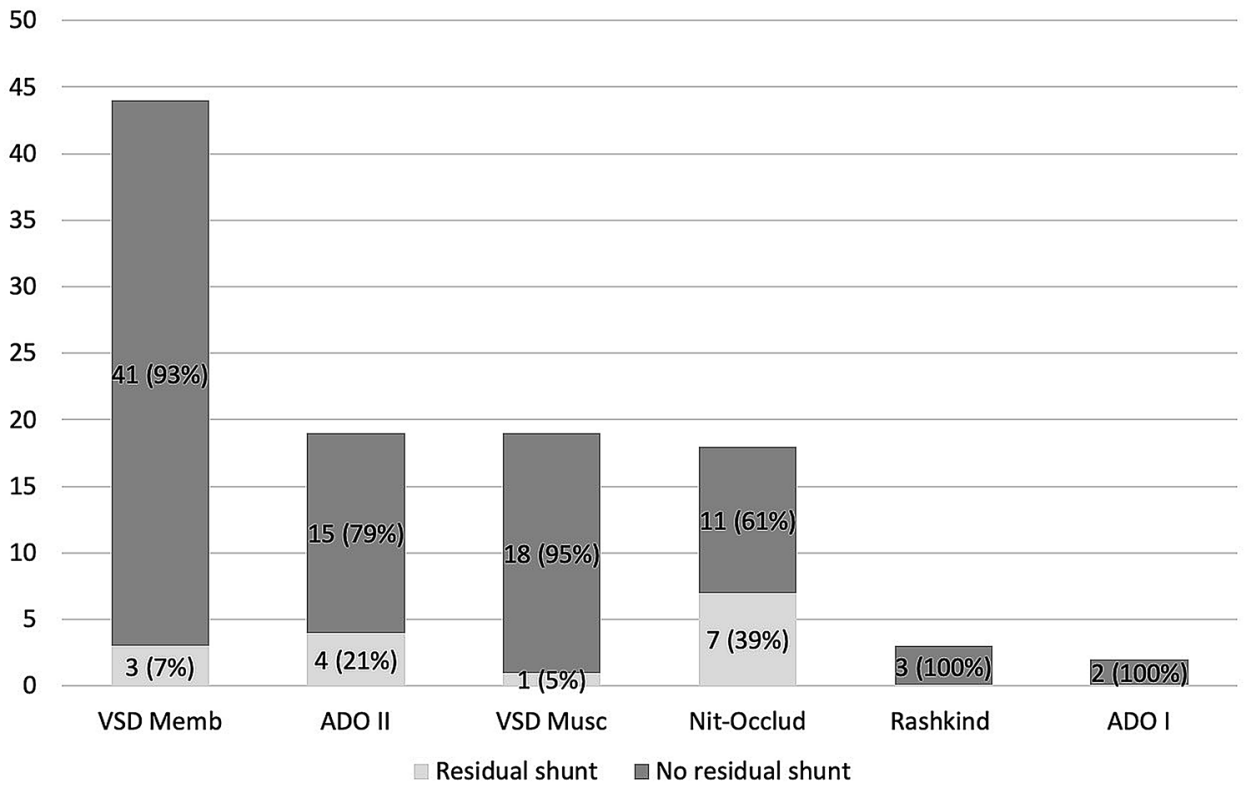

of the great arteries (TGA) was treated to close a residual VSD using a VSD Musc device and died 4 months later at the age of 2 years. It was impossible to find the cause of death in her medical records, but best possible follow-up revealed no signs of arrhythmia nor device malfunction.

\section{Discussion}

Today, percutaneous transcatheter VSD closure is an established treatment alternative. However, the success rate depends on the relation of VSD diameter and height/ weight of the child, as well as on the distance to the aortic and tricuspid valve [20]. Although relevant residual shunting and bradyarrhythmia (especially cAVB) are major concerns, only limited data are available with long-term follow-up for these issues [10, 19, 21-23]. In order to demonstrate the safety and performance of VSD devices in the long run, we focused on patients with at least 1-year follow-up after the procedure, since many publications only include short- or middle-term followup data [8, 23-25]. According to these data, we could achieve a long-term follow-up period of 6.2 (1.1-21.3) years. We included 155 procedures in 149 patients with 

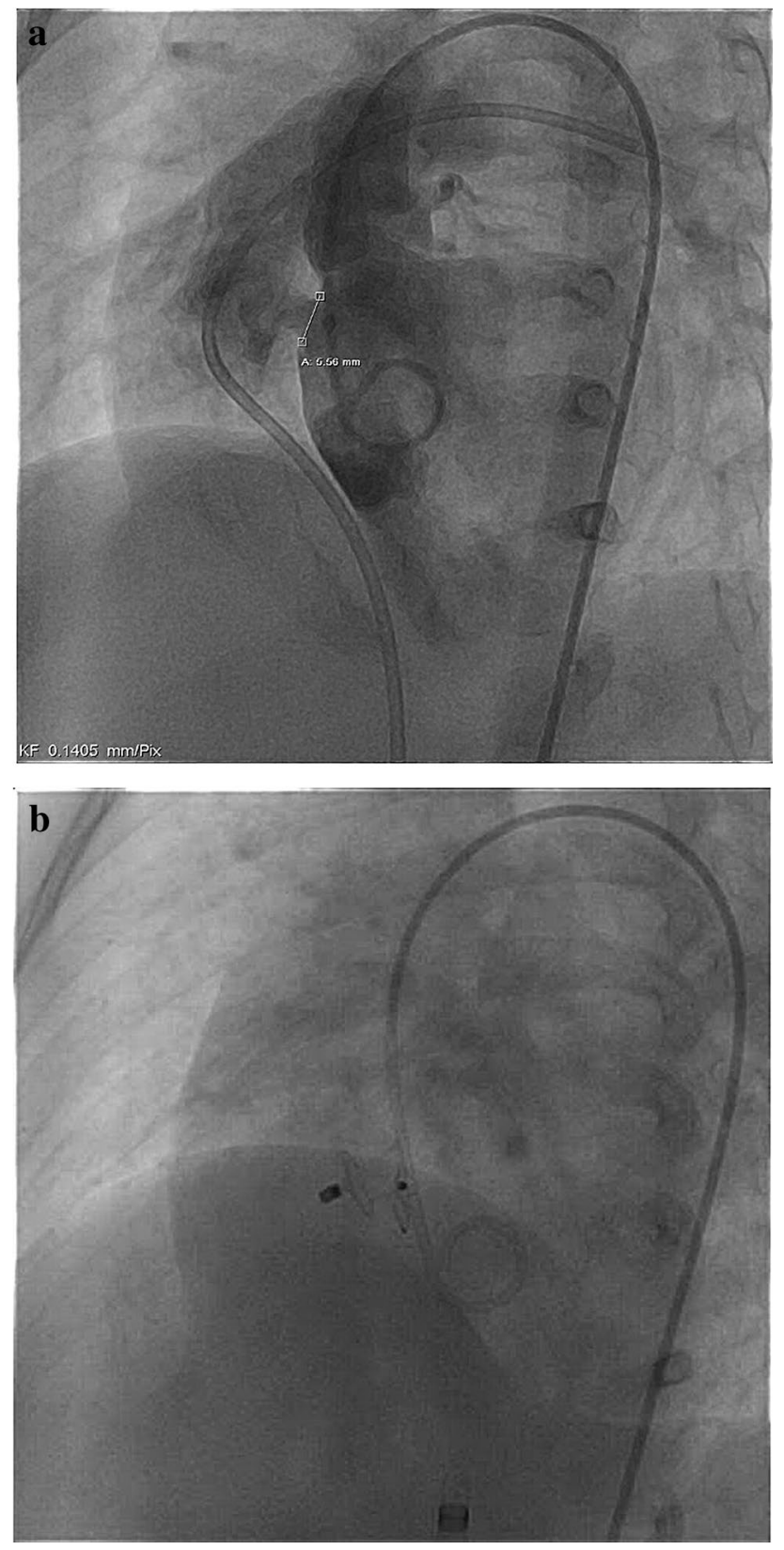

Fig. 3 a Membranous VSD (diameter $=5.56 \mathrm{~mm}$ ) with residual shunting; b Successfully implanted VSD Memb occluder $(6 \mathrm{~mm})$. "Oversized" configuration is visible in Fig. $2 b$, as indicated by an increased pressure related to the conduction tissue, which may be a cause for the early post-intervention detectable cAVB

$95.3 \%(142 / 149)$ by percutaneous and $4.7 \%$ (7/149) by hybrid approach. $47 \%$ (70/149) of the procedures were performed in the age between 1 and 10 years. Six different devices could be compared. This is in contrast to the majority of publications, analyzing only one type of device $[6,7,19]$ and only during short- or mid-term follow-up $[4,5]$.

\section{Residual Shunt}

A residual shunt rate of 3 to $29 \%$ has been reported in the past decades [4, 13, 22, 26, 27].

The overall residual shunt rate of $13.8 \%$ in our longterm cohort seems to be moderate and tolerable, but we have to emphasize that residual shunts were small and did caused relevant volume load over time. Nevertheless, the group with the Amplatzer ${ }^{\mathrm{TM}}$ Membranous and Musc VSD occluder showed the highest closure rate of $93-95 \%$, perhaps due to a better correlation between the diameter of the VSD and height of the child. Base on the technical issues of sheath size, possibility for implantation success, and complications, ADO II devices have been especially used in smaller children [19]. Moreover, the VSD occluder required a longer follow-up time in contrast to the more flexible and "off-label" used ADO II, thus, probable reasons for the higher closure rates observed for these devices $[5,6,8,13,23,26,28-30]$.

The residual shunt rate of $39 \%$ for the Nit-Occlud $®$ group observed in our cohort was higher in comparison to other studies, e.g., Haas et al. (5\% at 6 month, 3\% at 12 month, and no residual shunt after 4 years), Nguyen (5.9-8.7\% after 6 months), El Shedoudy et al. (2.5\% after 1 year), and Odemis et al. (15\% after 12.3 months). Remarkably, a new small but detectable shunt was again detected in one of our patients with the Nit-Occlud ${ }^{\circledR}$ 3 years after the procedure during pregnancy. This reopening of the shunt might be a result of increased cardiac output and ventricular dilatation during pregnancy $[7,9,31$, 32]. Therefore, residual shunting appears to be related to the device type and location of the VSD. We could demonstrate that post-surgical VSD and the Nit-Occlud® ${ }^{\circledR}$ device lead to higher residual shunt rates. Comparing different devices at different follow-up periods may be a reason for higher residual shunt rates. This has also been reported by Carminati et al., who observed a residual shunt rate of $17 \%$ at a median follow-up time of $2(0.5-10)$ years in 430 patients with 6 different devices [4].

\section{Arrhythmia}

The most feared complication of transcatheter VSD closure is cAVB with a reported incidence of $0-6.4 \%[7,25,28,30$, $32]$ and cAVB after surgical VSD closure has been reported with a prevalence of $1-5 \%$ [16, 33-35]. More current studies have reported cAVB rates between 1.25 and $1.4 \%$ for transcatheter VSD closure as a comparable risk after operation [9, 31, 36-39]. According to our data, we observed only $1 / 149$ (rate $0.7 \%$ ) patient with cAVB for all different VSD devices investigated during $>6$ years of follow-up, which is a lower rate than published data to date for interventional and 


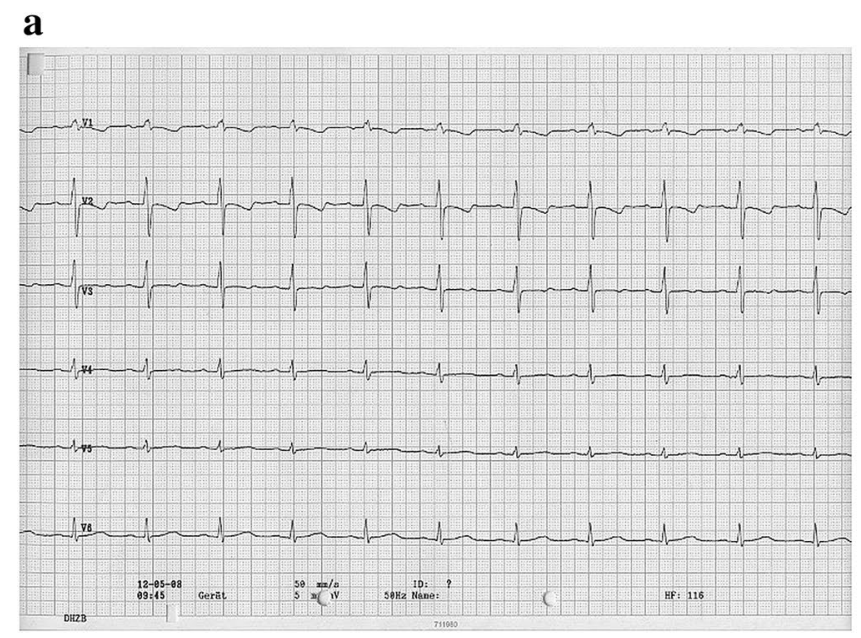

b

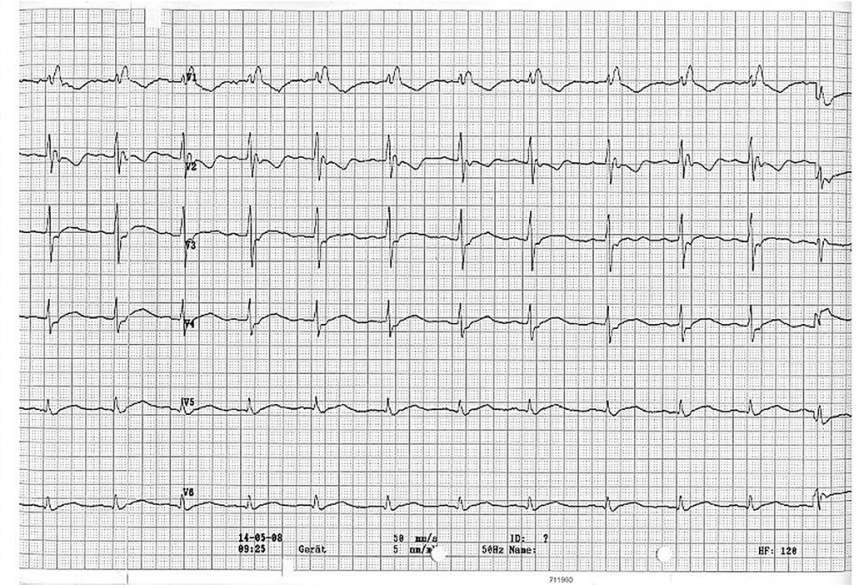

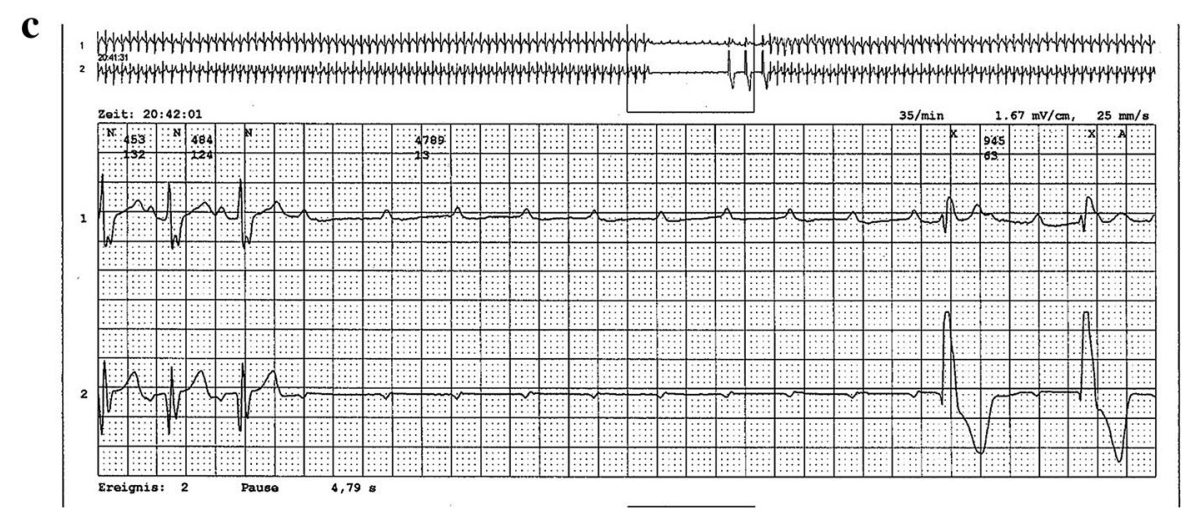

Fig. 4 a ECG prior intervention; b ECG post intervention showing a complete RBBB; $\mathbf{c}$ Holter-ECG with cAVB at day 7 post intervention

surgical approach. Cinteza et al. report early postoperative cAVB in contrast to an unclear or later manifestation of a block after the intervention. According to their understanding the early events are also device related and may be due to the thickness of nitinol wires [40]. The majority of cAVB are detected 2-7 days after the procedure, but late cAVB after 2-4 weeks or 10-20 months have also been reported in the literature [41-48]. In addition, a systematic review by Yang et al. reported 107 out of 4394 patients $(2.4 \%, 95 \%$ CI of 1.6-3.2) needed a permanent pacemaker after interventional procedure with a higher rate in younger children. In $86 \%(92 / 107)$ of these cases, the block manifested in the first week [27]. Although other studies also described late appearances of a cAVB [4, 49], long-term follow-up data are rare. Moreover, Carminati et al. summarized from their data that regular ECG controls are essential during followup $[4,50]$.

It appears to be possible that mechanical trauma, compression, inflammation, edema, and consecutive scarring resulting in a cAVB can be reduced, especially with the more flexible and softer devices such as ADO II [51-53]. Additionally, the use of oversized Amplatzer ${ }^{\mathrm{TM}}$ VSD devices needs to be avoided. We retrospectively speculate that this was a cofounding factor in our one patient who developed early cAVB. Other arrhythmias, including premature heart beats, tachycardia, and atrial or ventricular fibrillation are known risk factors for relevant temporary arrhythmia of $10.6 \%$ (95\% CI of 8.4-12.7) and persistent arrhythmia of $3.1 \%$ (95\% CI of 2.0-4.1) [27]. In our follow-up cohort, we observed $2.9 \%(3 / 105)$ tachyarrhythmia with an indication for therapy as tachycardia or atrial fibrillation. However, we did not observed a correlation to the procedure or device itself.

\section{Mortality}

We also analyzed all cases of mortality in both the short- and long-term follow-ups. Procedure-related mortality-rate was a low $0.7 \%$ (1/149 patients), and this particular patient died due to a complication from a hybrid approach for complex VSD 
closure. There was no device- or procedure-related mortality for the transfemoral approach. Two other children died within the first year of intervention due to treatment for univentricular or complex congenital cardiac disease, which was again not procedure- or device-related. In the long-term follow-up, another 3 patients died due to progression of biventricular heart failure or multiple organ failure with acute decompensation. In the literature, procedure-related deaths are rare (between 0 and 3\%) $[28,34]$. Wang et al. observed that the risk for major complications was significantly higher in children younger than 3 years old. Therefore, they recommend operations for patients with a VSD size larger than $10 \mathrm{~mm}$ or prolapse of the aortic valve [10]. In general, the literature shows different thresholds for percutaneous VSD occluder according to the increased risk of complications for patients below the threshold of $10 \mathrm{~kg}[8,13,54,55]$. Finally, all of these authors concluded that percutaneous transcatheter VSD closure is safe and effective. This is confirmed by our analysis pointing out no $(0 \%)$ device- or procedure-related mortality for the transfemoral approach.

Meta-analysis by Saurav et al. comparing operative and interventional VSD closure showed comparable effectivity and safety [17]. Today, radiation dosage during transcatheter VSD closure appears not to be a relevant risk factor anymore $[4,7]$. Moreover, hospital stay after catheter procedures is about 2.2 days shorter, costs less, and the general risks and complications associated with operations involving the heart lung machine and sternotomy can be avoided [16-19, 56-60]. Finally, it should not be left unmentioned that in general, the operative VSD cohort includes children who are younger with earlier symptoms and larger VSDs [27].

\section{Limitation}

A limitation of our study is the retrospective and singlecenter design. As successful implantation was an inclusion criteria for our study design, we did not analyze the success rate for this interventional procedure. Future prospective multicenter studies should reinforce the results with more powerful data. Finally, the long follow-up time of more than 20 years causes difficulties in comparability between the patients in our cohort, due to the development of new devices over this period. This means that different devices were not available for all patients at all times investigated. On the other hand, the long period of over 2 decades increases the validity of the results showing effectiveness and safety.

\section{Conclusion}

In conclusion, interventional VSD closure is becoming more important with growing experience and improving devices, and appears to be safe and effective for the majority of patients. Our results show that percutaneous VSD closure is a well-established procedure with a low severe adverse event rate. In our long-term follow-up group of 109 patients, we can report absence of cAVB and no late deaths were related to the procedure or the device. All residual shunts were small and did not caused relevant volume load or ventricular enlargement. Moreover, we identified the following two risk factors for residual shunting: VSDs after surgical closure and use of the Nit-Occlud ${ }^{\circledR}$ device. The only procedure-related death occurred in a patient treated by hybrid intervention. Based on common assumptions in the international literature, we speculate that the use of an oversized Membranous Amplatzer ${ }^{\mathrm{TM}}$ occluder may be the major reason for the development of cAVB in our patient. However, a prospective or randomized comparison of the impact from the device itself on the efficacy or complications is still needed.

To date, transcatheter VSD closure is being established as a safe and effective alternative for selected patients. The ongoing optimization of the existing devices, as well as development of newer and more flexible devices, such as the Lifetech Konar-MFTM VSD Occluder, may have the potential to further reduce the risk [61, 62].

Acknowledgements We would like to thank Giang Tong $(\mathrm{PhD})$ for editorial assistance.

Author Contributions All authors contributed to the study conception and design. Material preparation, data collection and analysis were performed by MB and CPG and SS. The first draft of the manuscript was written and revised by MB, CPG, and SS and all authors commented on previous versions of the manuscript. All authors read and approved the final manuscript.

Funding Open Access funding enabled and organized by Projekt DEAL.

\section{Compliance with Ethical Standards}

Conflict of interest Stephan Schubert is proctor/consultant for Abbott, Bentley, Edwards Lifetech and Medtronic. Felix Berger is proctor/consultant for Abbott and Medtronic.

Ethical Approval This study has received ethical approval (CharitéUniversitätsmedizin Berlin, Ref-Nr. EA2/129/15). 
Meeting Presentation 52nd Annual Meeting of the German Society for Pediatric Cardiology, Wiesbaden, Germany (March 2020).

Open Access This article is licensed under a Creative Commons Attribution 4.0 International License, which permits use, sharing, adaptation, distribution and reproduction in any medium or format, as long as you give appropriate credit to the original author(s) and the source, provide a link to the Creative Commons licence, and indicate if changes were made. The images or other third party material in this article are included in the article's Creative Commons licence, unless indicated otherwise in a credit line to the material. If material is not included in the article's Creative Commons licence and your intended use is not permitted by statutory regulation or exceeds the permitted use, you will need to obtain permission directly from the copyright holder. To view a copy of this licence, visit http://creativecommons.org/licenses/by/4.0/.

\section{References}

1. Lindinger A, Schwedler G, Hense HW (2010) Prevalence of congenital heart defects in newborns in Germany: results of the first registration year of the PAN Study (July 2006 to June 2007). Klin Padiatr 222(5):321-326

2. Duffels MGJ, Engelfriet PM, Berger RMF, van Loon RLE, Hoendermis E, Vriend JWJ, van der Velde ET, Bresser P, Mulder BJM (2007) Pulmonary arterial hypertension in congenital heart disease: an epidemiologic perspective from a Dutch registry. Int J Cardiol 120(2):198-204

3. Granton JT, Rabinovitch M (2002) Pulmonary arterial hypertension in congenital heart disease. Cardiol Clin 20(3):441-457

4. Carminati M, Butera G, Chessa M, De Giovanni J, Fisher G, Gewillig M, Peuster M, Piechaud JF, Santoro G, Sievert H, Spadoni I, Walsh K (2007) Transcatheter closure of congenital ventricular septal defects: results of the European Registry. Eur Heart J 28(19):2361-2368

5. Chungsomprasong P, Durongpisitkul K, Vijarnsorn C, Soongswang J, Le TP (2011) The results of transcatheter closure of VSD using Amplatzer(R) device and Nit Occlud(R) Le coil. Catheter Cardiovasc Interv 78(7):1032-1040

6. Ghaderian M, Merajie M, Mortezaeian H, Aarabi Moghadam MY, Shah Mohammadi A (2015) Mid-term follow-up of the transcatheter closure of perimembranous ventricular septal defects in children using the amplatzer. J Tehran Heart Cent 10(4):182-187

7. Haas NA, Kock L, Bertram H, Boekenkamp R, De Wolf D, Ditkivskyy I, Freund MW, Gewillig M, Happel CM, Herberg U, Karthasyan E, Kozlik-Feldmann R, Kretschmar O, Kuzmenko Y, Milanesi O, Mueller G, Pongiglione G, Schubert S, Tarusinov G, Kampmann C (2017) Interventional VSD-Closure with the Nit-Occlud((R)) Le VSD-Coil in 110 patients: early and midterm results of the EUREVECO-Registry. Pediatr Cardiol $38(2): 215-227$

8. Holzer R, de Giovanni J, Walsh KP, Tometzki A, Goh T, Hakim F, Zabal C, de Lezo JS, Cao QL, Hijazi ZM (2006) Transcatheter closure of perimembranous ventricular septal defects using the amplatzer membranous VSD occluder: immediate and midterm results of an international registry. Catheter Cardiovasc Interv 68(4):620-628

9. Nguyen HL, Phan QT, Dinh LH, Tran HB, Won H, Thottian JJ, Duc DD, Quang TN, Kim SW (2018) Nit-Occlud Le VSD coil versus Duct Occluders for percutaneous perimembranous ventricular septal defect closure. Congenit Heart Dis 13(4):584-593

10. Wang L, Cao S, Li J, Yang L, Liu Y, Ren J, Ma Q, Xing H, Li D, Tian D, Wan Y, Yu S, Chen T, Yang X, Yang J (2012)
Transcatheter closure of congenital perimembranous ventricular septal defect in children using symmetric occluders: an 8-year multiinstitutional experience. Ann Thorac Surg 94(2):592-598

11. Yang J, Yang L, Wan Y, Zuo J, Zhang J, Chen W, Li J, Sun L, Yu S, Liu J, Chen T, Duan W, Xiong L, Yi D (2010) Transcatheter device closure of perimembranous ventricular septal defects: midterm outcomes. Eur Heart J 31(18):2238-2245

12. Zhao LJ, Han B, Zhang JJ, Yi YC, Jiang DD, Lyu JL (2017) Postprocedural outcomes and risk factors for arrhythmias following transcatheter closure of congenital perimembranous ventricular septal defect: a single-center retrospective study. Chin Med J (Engl) 130(5):516-521

13. Zuo J, Xie J, Yi W, Yang J, Zhang J, Li J, Yi D (2010) Results of transcatheter closure of perimembranous ventricular septal defect. Am J Cardiol 106(7):1034-1037

14. Ergün S, Genç SB, Yildiz O, Öztürk E, Kafalı HC, Ayyıldız P, Haydin S (2019) Risk factors for major adverse events after surgical closure of ventricular septal defect in patients less than 1 year of age: a single-center retrospective. Braz J Cardiovasc Surg 34(3):335-343

15. Scully BB, Morales DL, Zafar F, McKenzie ED, Fraser CD Jr., Heinle JS (2010) Current expectations for surgical repair of isolated ventricular septal defects. Ann Thorac Surg 89(2):544-549

16. Mavroudis CB, Carl L (2003) Ventricular septal defect. Pediatr Card Surg 3:298-320

17. Saurav A, Kaushik M, Mahesh Alla V, White MD, Satpathy R, Lanspa T, Mooss AN, DelCore MG (2015) Comparison of percutaneous device closure versus surgical closure of peri-membranous ventricular septal defects: a systematic review and metaanalysis. Catheter Cardiovasc Interv 86(6):1048-1056

18. Yang J, Yang L, Yu S, Liu J, Zuo J, Chen W, Duan W, Zheng Q, Xu X, Li J, Zhang J, Xu J, Sun L, Yang X, Xiong L, Yi D, Wang L, Liu Q, Ge S, Ren J (2014) Transcatheter versus surgical closure of perimembranous ventricular septal defects in children: a randomized controlled trial. J Am Coll Cardiol 63(12):1159-1168

19. Kanaan M, Ewert P, Berger F, Assa S, Schubert S (2015) Follow-up of patients with interventional closure of ventricular septal defects with Amplatzer Duct Occluder II. Pediatr Cardiol 36(2):379-385

20. Dittrich S, Ewert P, Lê T-P, Schirmer KR, Hörer J (2010) Leitlinie Pädiatrische Kardiologie: Ventrikelseptumdefekt. 1-8

21. Li P, Zhao XX, Zheng X, Qin YW (2012) Arrhythmias after transcatheter closure of perimembranous ventricular septal defects with a modified double-disk occluder: early and long-term results. Heart Vessels 27(4):405-410

22. Rahmath MR, Numan M, Dilawar M (2016) Medium to longterm echo follow-up after ventricular septal defect device closure. Asian Cardiovasc Thorac Ann 24(5):422-427

23. Szkutnik M, Kusa J, Bialkowski J (2008) Percutaneous closure of perimembranous ventricular septal defects with Amplatzer occluders-a single centre experience. Kardiol Pol 66(9):941-947

24. Fu YC, Bass J, Amin Z, Radtke W, Cheatham JP, Hellenbrand WE, Balzer D, Cao QL, Hijazi ZM (2006) Transcatheter closure of perimembranous ventricular septal defects using the new Amplatzer membranous VSD occluder: results of the U.S. phase I trial. J Am Coll Cardiol 47(2):319-325

25. Koneti NR, Sreeram N, Penumatsa RR, Arramraj SK, Karunakar V, Trieschmann U (2012) Transcatheter retrograde closure of perimembranous ventricular septal defects in children with the Amplatzer duct occluder II device. J Am Coll Cardiol 60(23):2421-2422

26. Knop MT, Litwin L, Szkutnik M, Bialkowski J, Galeczka M, Fiszer R (2018) Percutaneous closure of perimembranous and postsurgical ventricular septal defects with Amplatzer Duct Occluder II Additional Sizes in paediatric patients - case series. Postepy Kardiol Interwencyjnej 14(4):429-432 
27. Yang L, Tai BC, Khin LW, Quek SC (2014) A systematic review on the efficacy and safety of transcatheter device closure of ventricular septal defects (VSD). J Interv Cardiol 27(3):260-272

28. Chessa M, Butera G, Negura D, Bussadori C, Giamberti A, Fesslova V, Carminati M (2009) Transcatheter closure of congenital ventricular septal defects in adult: mid-term results and complications. Int J Cardiol 133(1):70-73

29. Pamukcu O, Narin N, Baykan A, Sunkak S, Tasci O, Uzum K (2017) Mid-term results of percutaneous ventricular septal defect closure with Amplatzer Duct Occluder-II in children. Cardiol Young 27(9):1726-1731

30. Vijayalakshmi IB, Narasimhan C, Singh B, Manjunath CN (2017) Treatment of congenital non-ductal shunt lesions with the amplatzer duct occluder II. Catheter Cardiovasc Interv 89(6):E185-e193

31. El Shedoudy S, El-Doklah E (2019) Mid-term results of transcatheter closure of ventricular septal defect using Nit-Occlud Le ventricular septal defect coil, single-center experience. J Saudi Heart Assoc 31(2):78-87

32. Odemis E, Saygi M, Guzeltas A, Tanidir IC, Ergul Y, Ozyilmaz I, Bakir I (2014) Transcatheter closure of perimembranous ventricular septal defects using Nit-Occlud((R)) Le VSD coil: early and mid-term results. Pediatr Cardiol 35(5):817-823

33. Bol-Raap G, Weerheim J, Kappetein AP, Witsenburg M, Bogers AJ (2003) Follow-up after surgical closure of congenital ventricular septal defect. Eur J Cardiothorac Surg 24(4):511-515

34. Knauth AL, Lock JE, Perry SB, McElhinney DB, Gauvreau $\mathrm{K}$, Landzberg MJ, Rome JJ, Hellenbrand WE, Ruiz CE, Jenkins KJ (2004) Transcatheter device closure of congenital and postoperative residual ventricular septal defects. Circulation 110(5):501-507

35. Roos-Hesselink JW, Meijboom FJ, Spitaels SE, Van Domburg R, Van Rijen EH, Utens EM, Bogers AJ, Simoons ML (2004) Outcome of patients after surgical closure of ventricular septal defect at young age: longitudinal follow-up of 22-34 years. Eur Heart J 25(12): 1057-1062

36. Andersen HO, de Leval MR, Tsang VT, Elliott MJ, Anderson $\mathrm{RH}$, Cook AC (2006) Is complete heart block after surgical closure of ventricular septum defects still an issue? Ann Thorac Surg 82(3):948-956

37. Edwin F, Aniteye E, Tettey M, Sereboe L, Kotei D, Tamatey M, Entsua-Mensah K, Frimpong-Boateng K (2010) Permanent complete heart block following surgical correction of congenital heart disease. Ghana Med J 44(3):109-114

38. Ghaderian M, Merajie M, Mortezaeian H, Aarabi M, Mohammad Y, ShahMohammadi A (2015) Efficacy and safety of using amplatzer ductal occluder for transcatheter closure of perimembranous ventricular septal defect in pediatrics. Iran J Pediatr 25(2): 3386

39. Siehr SL, Hanley FL, Reddy VM, Miyake CY, Dubin AM (2014) Incidence and risk factors of complete atrioventricular block after operative ventricular septal defect repair. Congenit Heart Dis 9(3):211-215

40. Cinteza EE, Butera G (2016) Complex ventricular septal defects. Update on percutaneous closure. Rom J Morphol Embryol 57(4):1195-1205

41. Hornung M, Franke J, Id D, Sievert H (2015) Interventional closure of atrial septal defects, patent oval foramen and ventricular septal defects. Herz 40(5):765-770

42. Masura J, Gao W, Gavora P, Sun K, Zhou AQ, Jiang S, TingLiang L, Wang Y (2005) Percutaneous closure of perimembranous ventricular septal defects with the eccentric Amplatzer device: multicenter follow-up study. Pediatr Cardiol 26(3):216-219

43. Predescu D, Chaturvedi RR, Friedberg MK, Benson LN, Ozawa A, Lee KJ (2008) Complete heart block associated with device closure of perimembranous ventricular septal defects. J Thorac Cardiovasc Surg 136(5):1223-1228

44. Walsh MA, Bialkowski J, Szkutnik M, Pawelec-Wojtalik M, Bobkowski W, Walsh KP (2006) Atrioventricular block after transcatheter closure of perimembranous ventricular septal defects. Heart 92(9):1295-1297

45. Yalonetsky S, Lorber A (2009) Late high degree atrioventricular block after percutaneous closure of a perimembranous ventricular septal defect. Cardiol Young 19(3):298-300

46. Yang R, Sheng Y, Cao K, Kong X, Xu D, Yong Y, Zhou L, Zhang H, Qian L, Sun W, Gu Z (2011) Transcatheter closure of perimembranous ventricular septal defect in children: safety and efficiency with symmetric and asymmetric occluders. Catheter Cardiovasc Interv 77(1):84-90

47. Yip WC, Zimmerman F, Hijazi ZM (2005) Heart block and empirical therapy after transcatheter closure of perimembranous ventricular septal defect. Catheter Cardiovasc Interv 66(3):436-441

48. Zhu XY, Liu YH, Hou CJ, Han XM, Sheng XT, Zhang DZ, Cui CS, Wang QG, Deng DA, Zhang YW (2007) Risk factors for early arrhythmias post transcatheter closure of perimembranous ventricular septal defects. Zhonghua Xin Xue Guan Bing Za Zhi 35(7):633-636

49. Butera G, Carminati M, Chessa M, Piazza L, Micheletti A, Negura DG, Abella R, Giamberti A, Frigiola A (2007) Transcatheter closure of perimembranous ventricular septal defects: early and longterm results. J Am Coll Cardiol 50(12):1189-1195

50. Bentham JR, Gujral A, Adwani S, Archer N, Wilson N (2011) Does the technique of interventional closure of perimembranous ventricular septal defect reduce the incidence of heart block? Cardiol Young 21(3):271-280

51. Bass JL, Gruenstein D (2012) Transcatheter closure of the perimembranous ventricular septal defect-preclinical trial of a new Amplatzer device. Catheter Cardiovasc Interv 79(7):1153-1160

52. El Said HG, Bratincsak A, Gordon BM, Moore JW (2012) Closure of perimembranous ventricular septal defects with aneurysmal tissue using the Amplazter Duct Occluder I: lessons learned and medium term follow up. Catheter Cardiovasc Interv 80(6):895-903

53. Erdem S, Kizlltas A, Kucukosmanoglu O, Ozbarlas N (2012) Temporary atrioventricular complete block that develops following the transcatheter closure of ventricular septal defect. Turk J Pediatr 54(1):80-82

54. Hammon JW Jr. (1995) Myocardial protection in the immature heart. Ann Thorac Surg 60(3):839-842

55. Qin Y, Chen J, Zhao X, Liao D, Mu R, Wang S, Wu H, Guo H (2008) Transcatheter closure of perimembranous ventricular septal defect using a modified double-disk occluder. Am J Cardiol 101(12):1781-1786

56. Borges F, Sparano A, Robles Y, Urbano E, Hermanni M, Garcia C, Zabala R, Villoria G, Acuñ M, Castro H, Bravo R, Ramirez E, Troconis C (2016) Percutaneous transcatheter closure of perimembranous ventricular septal defects in one working group, long-term follow up. J Pediatr Neonatal Care 5(1):00168

57. Hobbins SM, Izukawa T, Radford DJ, Williams WG, Trusler GA (1979) Conduction disturbances after surgical correction of ventricular septal defect by the atrial approach. Br Heart J 41(3):289-293

58. O’Byrne ML, Gillespie MJ, Shinohara RT, Dori Y, Rome JJ, Glatz AC (2015) Cost comparison of transcatheter and operative closures of ostium secundum atrial septal defects. Am Heart J 169(5):727-735.e2

59. Pischke SE, Tronstad C, Holhjem L, Halvorsen PS, Tonnessen TI (2012) Perioperative detection of myocardial ischaemia/reperfusion with a novel tissue $\mathrm{CO}_{2}$ monitoring technology. Eur J Cardiothorac Surg 42(1):157-163 
60. Quek SC, Hota S, Tai BC, Mujumdar S, Tok MY (2010) Comparison of clinical outcomes and cost between surgical and transcatheter device closure of atrial septal defects in Singapore children. Ann Acad Med Singapore 39(8):629-633

61. Haddad RN, Daou LS, Saliba ZS (2019) Percutaneous closure of restrictive-type perimembranous ventricular septal defect using the new KONAR multifunctional occluder: midterm outcomes of the first middle-eastern experience. Catheter Cardiovasc Interv. https://doi.org/10.1002/ccd.28678
62. Schubert S, Kelm M, Koneti NR, Berger F (2019) First European experience of percutaneous closure of ventricular septal defects using a new CE-marked VSD occluder. EuroIntervention 15(3):e242-e243

Publisher's Note Springer Nature remains neutral with regard to jurisdictional claims in published maps and institutional affiliations. 